\title{
A Study on the Attitude of the Hindu and Christian Secondary School Teachers of Malda and Murshidabad Districts, West Bengal, India towards Yoga Education in Schools in Relation to their Mental Health
}

\author{
MD. Afsar Ali \\ Principal, Saheed Nurul Islam Mahavidyalaya, Swarupnagar, West Bengal, India. \\ E-mail: ali.mdafsar09@gmail.com
}

\begin{abstract}
This is a study on the attitude of the secondary school teachers towards yoga education in schools in relation to their religious belief and mental health. Stratified purposeful sampling method was used. A significant difference in attitude towards yoga education was observed at 0.01 level between Hindu and Christian secondary school teachers of Malda and Murshidabad districts, West Bengal, India. The Hindu teachers possessing better mental health show better attitude towards yoga education in comparison to their Christian counterpart. The male teachers of government schools from Hindu vs. Christian religious faith show significant difference in attitude towards yoga education than their female counterpart. No significant difference in attitude towards yoga education in schools was observed between the male and female private school teachers of Malda district. However, the reverse is true for Murshidabad district.

Keywords: Attitude, Mental Health, Religion, Teacher, Yoga Education, India.
\end{abstract}

\section{INTRODUCTION}

That our education curriculum has failed to give a balanced development of our body and mind along with the muchfocused development of brain is being reflected through the 'educated persons' many inhuman, restless and stressful day-to-day activities. Thus, a valid question is arising from many corners of the worried society regarding the accountability of the education system in general and the school curriculum in shaping human baby into human being. More the days are passing, more incompleteness in the system of education are getting exposed and thus more prominent becoming that accountability question. Now-adays, a section of Indian society including the government, many times come with the prescription that yoga education is the remedy to complete the incompleteness whatsoever there in the system of education. In their opinion, yoga provides the two important ' $\mathrm{H}$ ' (i.e., education for Health and education for Heart - means, humanity) to the education curriculum meant for development of human children, which are lacking presently in the heavily tilted curriculum towards the development of another two ' $\mathrm{H}$ ' (Head and Hands, means cognitive and skill).

In this background, there arise a strong need to have a scientific study on the attitude of different sections of Indian society, which is intensely diversified in terms of religion, culture, geographical location and of course in gender, towards the question of yoga education in schools. But in the extensive literature survey conducted by this author he came across none such study! Thus, the main objective of this study was the basic question that whether inclusion of yoga education in school curriculum can make up this incompleteness in educating our children? - As the teachers are the inherent and the most important component of education, so, they are chosen as the population of this study. Naturally, the main problem of this study is conversed as - what is the attitude of secondary school teachers towards yoga education in schools?

\section{METHODOLOGY}

The following method was followed in this research work -

\section{A. Coverage}

I. Universe: The universe of this study is all the teachers serving in substantive posts in secondary schools affiliated to any legal authority (board /council /others) in Malda and Murshidabad districts, West Bengal, India.

II. Sample: A total of 400 samples were selected from the above universe, as per the sampling from the above universe, as per the sampling frame presented below-

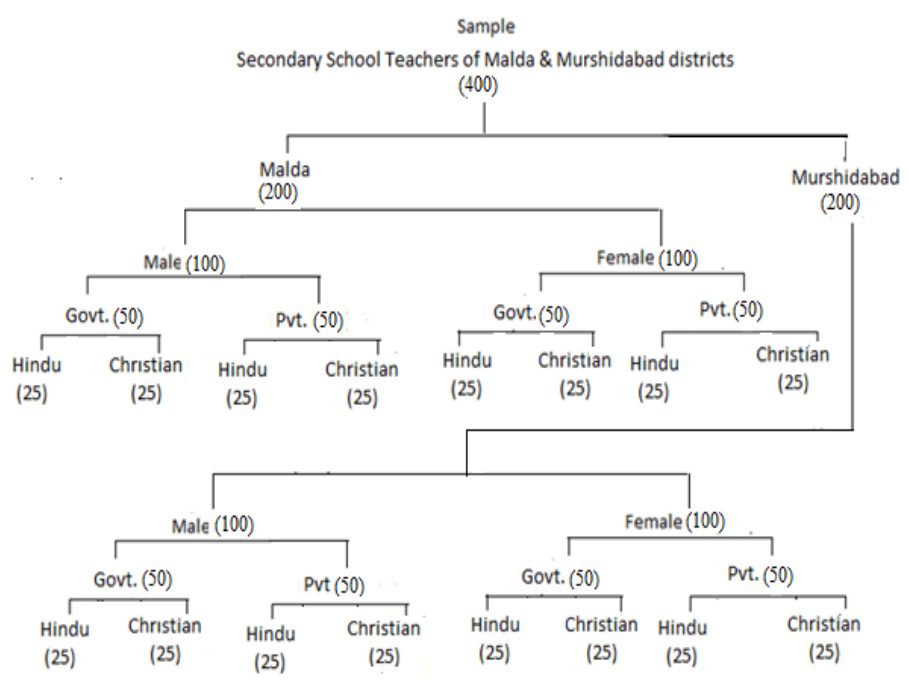

Fig.1 Sampling Frame 
III. Sampling Method: Stratified purposeful sampling method was used in order to ensure the representation of the population in respect of all the independent variables as per the above sampling frame.

IV. Sampling Size: 400 numbers of samples as per the above sampling frame.

V. Units of Observation: The teachers were given the questionnaires (of yoga and mental health - separately) individually or in small groups of 5 members, for the purpose of collecting their attitude towards yoga education in schools as well as to know their mental health type.

\section{B.Variables}

The dependent and independent variables in this study are

I. Dependent Variables: Attitude towards Yoga Education, and Mental Health.

II. Independent Variables: Religion, Geographical Location, Gender, and School Management.

\section{Tools Used}

\section{Attitude towards Yoga Education Scale}

The final form of the attitude scale contains 46 items [with Facility Value (FV) and Index of Discrimination (ID) both within 0.25 to 0.80 ] covering all the fields / factors affecting yoga education. There were 24 favourable and 22 unfavourable items in the questionnaire. The reliability coefficient by test-retest method was to be of good value, 0.88 . The content validity of the scale was verified by several specialists in the relevant field. The items in the test proportionally represent the different dimensions of the variable so far their weight age is concerned. Hence, the scale has good content validity.

\section{The Mental Health Inventory}

To measuring the mental health of the secondary schools' teachers, a mental health inventory, prepared and standardized by Jagadish and Srivastava, was purchased from National Psychological Corporation, Agra, U.P., India. As this inventory was standardized long ago, in 1983, so the inventory was re-standardized to contextualize to the present socio-mental setup. After re-standardization, the items with FV of $20 \%$ to $47.82 \%$ and with ID value of 0.25 to 0.71 were retained and the rest were rejected. Thus, a total of 56 items in the original form of the inventory came down to 45 items only with 23 true keyed (positive) /favourable and 22 false keyed (negative) /unfavourable ones. Reliability co-efficient of this inventory (by test retest method) was found to be of good value, 0.85 . The content of the inventory and its specification was verified by several specialists in the relevant field. The item in the test proportionally represents the different dimensions of the variable, so far, their weight age is concerned, the inventory represents good content validity.

\section{Data Collection}

The data for this study were collected through face-to-face structured interview with the samples with the help of the above two tools. Before handing over the questionnaire /inventory to the subjects, necessary rapport was established with them. Then, the aims and objectives of the study were clearly mentioned before them. Thereafter, the necessary instructions for properly responding the items were cleared. After the expiry of the assigned time period, the questionnaires /inventories were collected for data analysis.

\section{E. Data Analysis}

The collected data were analyzed through descriptive as well as inferential statistics like ANOVA, 't'-test by applying SPSS (Version 17) software.

\section{F. Research Questions / Hypotheses}

Hypothesis No. $\mathrm{H}_{1}$ : The attitude towards yoga education in schools between Hindu and Christian secondary school teachers of Malda and Murshidabad districts, West Bengal differs significantly.

Hypothesis No. $\mathrm{H}_{2}$ : There is a positive relation between mental health and attitude towards yoga education in schools between Hindu and Christian secondary school teachers of Malda and Murshidabad districts, West Bengal, which differs significantly.

\section{RESULTS AND DISCUSSION}

The result of this study is presented below in tabular forms with a brief and relevant discussion. Table 1: The table below depicts the comparison in attitude between Hindu vs. Christian secondary school teachers in Malda and Murshidabad districts, West Bengal, India, towards yoga education in secondary schools vis-à-vis their mental health:

TABLE I ATTITUDE BETWEEN HINDU VS. CHRISTIAN SECONDARY SCHOOL TEACHERS

\begin{tabular}{|c|c|c|c|c|c|c|c|c|c|}
\hline \multirow{2}{*}{$\begin{array}{c}\text { Comparison } \\
\text { Between } \\
\text { Groups }\end{array}$} & \multirow{2}{*}{$\begin{array}{c}\text { Sample } \\
\text { No. }\end{array}$} & \multicolumn{6}{|c|}{ Attitude towards Yoga Education } & \multicolumn{2}{|c|}{ Mental Health } \\
\hline & & Mean & S. D. & Variance & Df & F-value & t-value & Score (Av.) & Type \\
\hline Hindu & 200 & 93.75 & 11.19 & 125.22 & \multirow{2}{*}{398} & \multirow{2}{*}{28.40} & \multirow{2}{*}{$5.33 *$} & 122.88 & Very Poor \\
\hline Christian & 200 & 88.93 & 6.20 & 38.44 & & & & 119.38 & Very Poor \\
\hline
\end{tabular}


Table I illustrates a significant difference in attitude towards yoga education at 0.01 level between the Hindu (93.75 \pm 11.19) and Christian (88.93 \pm 6.20$)$ secondary school teachers of Malda and Murshidabad district. So, hypothesis no. $\mathrm{H}_{1}$ is verified and retained.
The teachers with better mental health (Hindu, 122.88) possess better attitude towards yoga education than the lower mental health type teachers (Christian, 119.38). Thus, hypothesis no. $\mathrm{H}_{2}$ is retained. This attitudinal difference is pictorially presented in fig. 2 below:

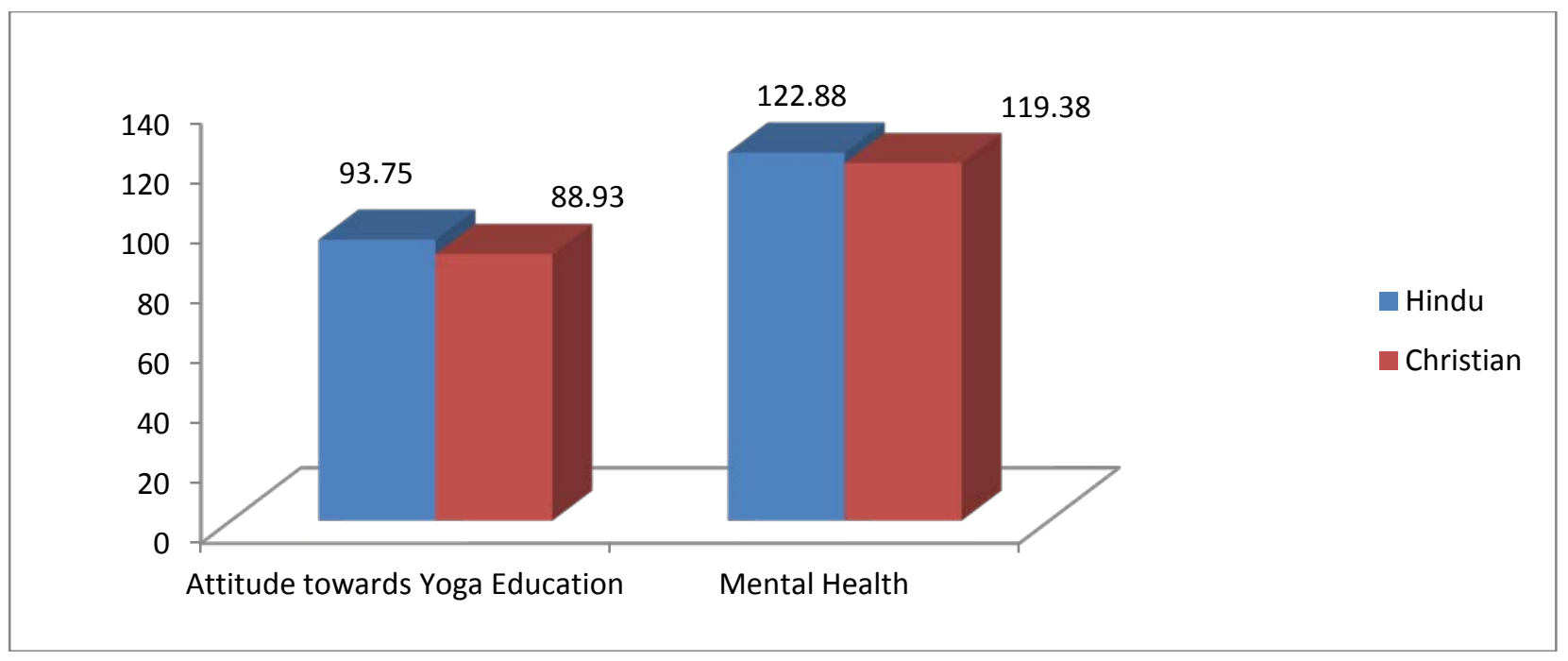

Fig.2 Difference in attitude between Hindu and Christian teachers in secondary schools in Malda and Murshidabad districts, W.B., India, towards yoga education in schools and their mental health.

Table II: The table below depicts the comparison in attitude between Hindu vs. Christian male teachers of government managed secondary schools in Malda district, West Bengal,
India, towards yoga education in secondary schools vis-àvis their mental health:

TABLE II ATTITUDE BETWEEN HINDU VS. CHRISTIAN MALE TEACHERS OF GOVERNMENT MANAGED SECONDARY SCHOOLS

\begin{tabular}{|l|c|c|c|c|c|c|c|c|c|}
\hline Comparison & \multirow{2}{*}{$\begin{array}{c}\text { Between } \\
\text { Groups }\end{array}$} & $\begin{array}{c}\text { Sample } \\
\text { No. }\end{array}$ & \multicolumn{4}{|c|}{ Attitude towards Yoga Education } & \multicolumn{3}{c|}{ Mental Health } \\
\cline { 1 - 10 }$n$ & Mean & S. D. & Variance & Df & F-value & t-value & Score (Av.) & Type \\
\hline Hindu & 25 & 96.88 & 18.48 & 341.44 & \multirow{2}{*}{48} & \multirow{2}{*}{6.53} & $2.55 *$ & 114.80 & Very Poor \\
\hline Christian & 25 & 87.24 & 3.79 & 14.36 & & & & 119.12 & Very Poor \\
\hline
\end{tabular}

Table illustrates that there is a significant difference in attitude towards yoga education at 0.02 level between the male, Hindu (96.88 \pm 18.48) and Christian (87.24 \pm 3.79) teachers in government managed secondary schools in Malda district. The teachers with better mental health
(Christian, 119.92) show lower attitude towards yoga education than the lower mental health type teachers (Hindu, 114.80). This attitudinal difference is pictorially presented in fig.2 (i) below: 
A Study on the Attitude of the Hindu and Christian Secondary School Teachers of Malda and Murshidabad Districts, West Bengal, India towards Yoga Education in Schools in Relation to their Mental Health

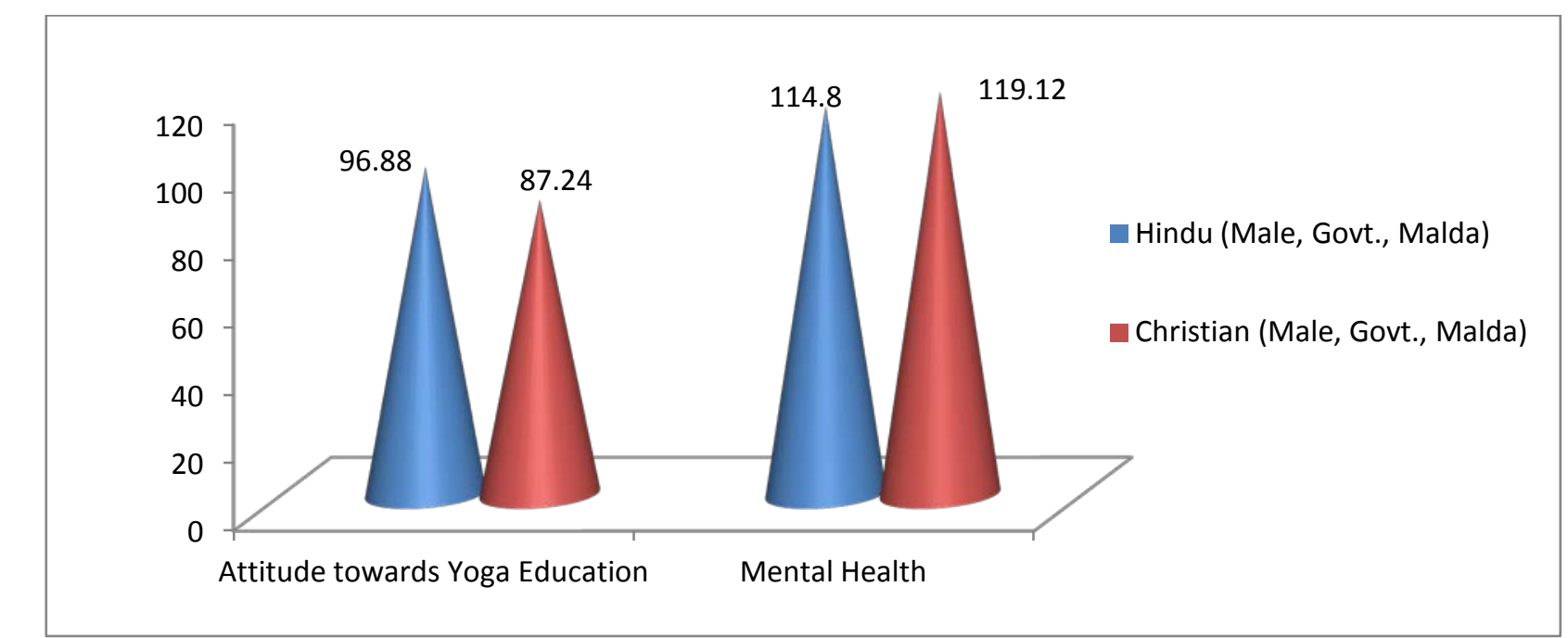

Fig.2 (i): Difference in attitude between male, Hindu and Christian govt. managed secondary school teachers in Malda district, W.B., India, towards yoga education and their mental health.

Table III: The table below depicts the comparison in attitude between Hindu vs. Christian female teachers in government managed secondary schools in Malda district, West Bengal,
India, towards yoga education in secondary schools vis-àvis their mental health:

\section{TABLE III ATTITUDE BETWEEN HINDU VS. CHRISTIAN FEMALE TEACHERS IN GOVERNMENT MANAGED SECONDARY SCHOOLS}

\begin{tabular}{|c|c|c|c|c|c|c|c|c|c|}
\hline \multirow{2}{*}{$\begin{array}{c}\text { Comparison } \\
\text { Between } \\
\text { Groups } \\
\end{array}$} & \multirow{2}{*}{$\begin{array}{c}\text { Sample } \\
\text { No. }\end{array}$} & \multicolumn{6}{|c|}{ Attitude towards Yoga Education } & \multicolumn{2}{|c|}{ Mental Health } \\
\hline & & Mean & S. D. & Variance & Df & F-value & t-value & Score (Av.) & Type \\
\hline Hindu & 25 & 89.56 & 10.51 & 110.42 & \multirow{2}{*}{48} & \multirow{2}{*}{0.16} & \multirow{2}{*}{$0.40 *$} & 134.08 & Poor \\
\hline Christian & 25 & 90.72 & 4.42 & 19.54 & & & & 133.68 & Poor \\
\hline
\end{tabular}

From table 1(ii) it is clear that there is no significant difference in attitude towards yoga education at 0.05 level between the female, Hindu $(89.56 \pm 10.51)$ and Christian (90.72 \pm 4.42$)$ teachers in government managed secondary school teachers in Malda district, W.B., India. The teachers with better mental health (Hindu, 134.08) shows lower attitude towards yoga education than the lower mental health type teachers (Hindu, 133.68). This attitudinal difference is pictorially presented below in fig.2 (ii):

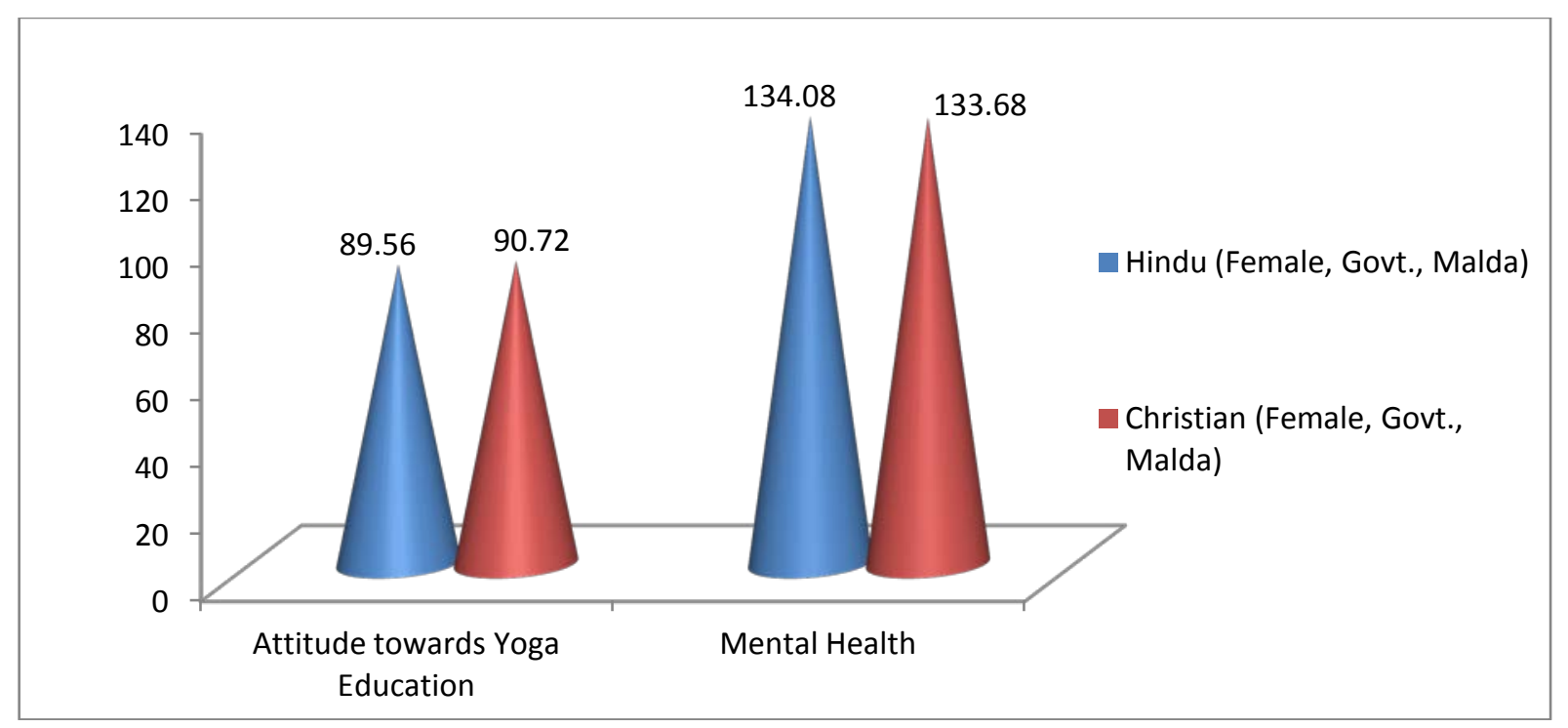

Fig. 2 (ii): Difference in attitude between female, Hindu and Christian teachers in govt. managed secondary schools in Malda district, W.B., India towards yoga education and their mental health 
Table above show that the Christian female teachers in Govt. managed schools show better attitude towards yoga education in schools than their Hindu counterpart (Patel, 2017). Comparing the tables 1(i) and 1(ii), the Hindu male teachers show better attitude towards yoga education than the female Hindu teachers (Khatun, 2016).
Table IV: The table below depicts the comparison in attitude between Hindu vs. Christian male teachers in privately managed secondary schools in Malda district, West Bengal, India, towards yoga education in secondary schools vis-à-vis their mental health:

TABLE IV ATTITUDE BETWEEN HINDU VS. CHRISTIAN MALE TEACHERS IN PRIVATELY MANAGED SECONDARY SCHOOLS

\begin{tabular}{|l|c|c|c|c|c|c|c|c|c|}
\hline \multirow{2}{*}{$\begin{array}{c}\text { Comparison } \\
\text { Between } \\
\text { Groups }\end{array}$} & \multirow{2}{*}{$\begin{array}{c}\text { Sample } \\
\text { No. }\end{array}$} & \multicolumn{4}{|c|}{ Attitude towards Yoga Education } & \multicolumn{3}{c|}{ Mental Health } \\
\cline { 3 - 10 }$n$ & Mean & S. D. & Variance & Df & $\begin{array}{c}\text { F- } \\
\text { value }\end{array}$ & t-value & Score (Av.) & Type \\
\hline Hindu & 25 & 87.76 & 4.84 & 23.42 & \multirow{2}{*}{48} & 78.13 & $8.84 *$ & 110.40 & Very Poor \\
\hline Christian & 25 & 99.48 & 4.53 & 20.52 & & & & 113.04 & Very Poor \\
\hline
\end{tabular}

Table clearly reveals that there is a significant difference in attitude towards yoga education at 0.01 level between the male, Hindu (87.76 \pm 4.84$)$ and Christian (99.48 \pm 4.53) teachers in privately managed secondary schools in Malda district. The teachers with better mental health (Christian, 113.04) show better attitude towards yoga education than the teachers with lower mental health (Hindu, 110.40). This attitudinal difference is pictorially presented below in fig.2 (iii):

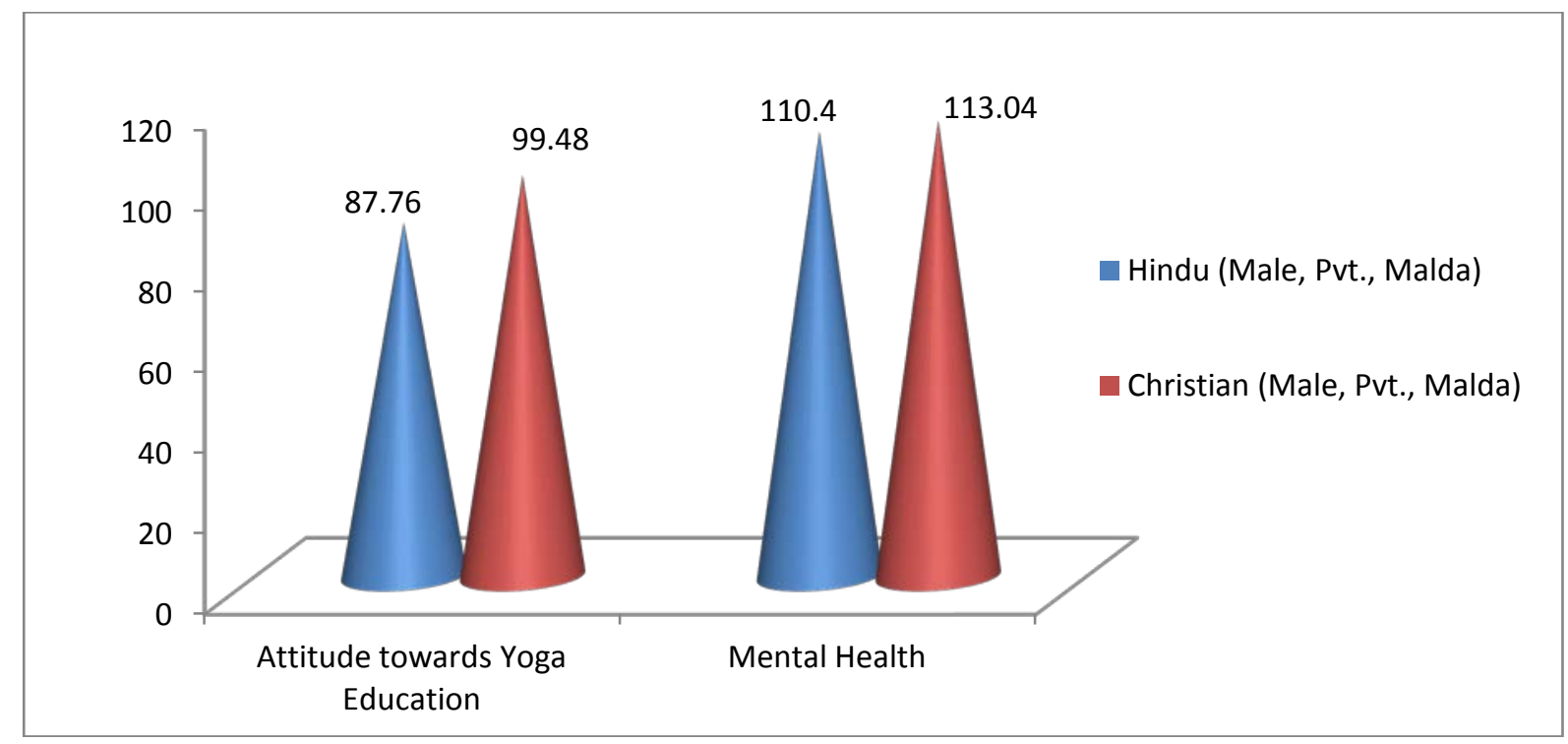

Fig. 2 (iii): Difference in attitude between male, Hindu and Christian teachers in privately managed secondary schools in Malda district, W.B., India, towards yoga education and their mental health

The tables 1(i) and 1(iii) above reveal that the Christian teachers in privately managed schools show better attitude towards yoga education than their counterpart in government schools (Singh \& Dubey, 2015). However, a decline in attitude towards yoga education was observed among the Hindu teachers here.
Table V: The table below depicts the comparison in attitude between Hindu vs. Christian female teachers in privately managed secondary schools in Malda district, West Bengal, India, towards yoga education in secondary schools vis-àvis their mental health:

TABLE V ATTITUDE BETWEEN HINDU VS. CHRISTIAN FEMALE TEACHERS IN PRIVATELY MANAGED SECONDARY SCHOOLS

\begin{tabular}{|c|c|c|c|c|c|c|c|c|c|}
\hline \multirow{2}{*}{$\begin{array}{c}\text { Comparison } \\
\text { Between } \\
\text { Groups } \\
\end{array}$} & \multirow{2}{*}{$\begin{array}{c}\text { Sample } \\
\text { No. }\end{array}$} & \multicolumn{6}{|c|}{ Attitude towards Yoga Education } & \multicolumn{2}{|c|}{ Mental Health } \\
\hline & & Mean & S. D. & Variance & Df & F-value & t-value & $\begin{array}{l}\text { Score } \\
\text { (Av.) }\end{array}$ & Type \\
\hline Hindu & 25 & 92.36 & 4.35 & 18.92 & \multirow[b]{2}{*}{48} & \multirow{2}{*}{36.00} & \multirow{2}{*}{$6.00 *$} & 134.00 & Poor \\
\hline Christian & 25 & 88.12 & 3.86 & 14.90 & & & & 120.88 & $\begin{array}{l}\text { Very } \\
\text { Poor }\end{array}$ \\
\hline
\end{tabular}


From the table 1(iv) it can be inferred that there is a significant difference in attitude towards yoga education at 0.01 level between the female, Hindu $(92.36 \pm 4.35)$ and Christian (88.12 \pm 3.86$)$ teachers in privately managed secondary schools in Malda district. The teachers with better mental health (Hindu, 134.00) show better attitude towards yoga education than the lower mental health type teachers (Christian, 120.88). This attitudinal difference is pictorially presented in fig.2 (iv) below:

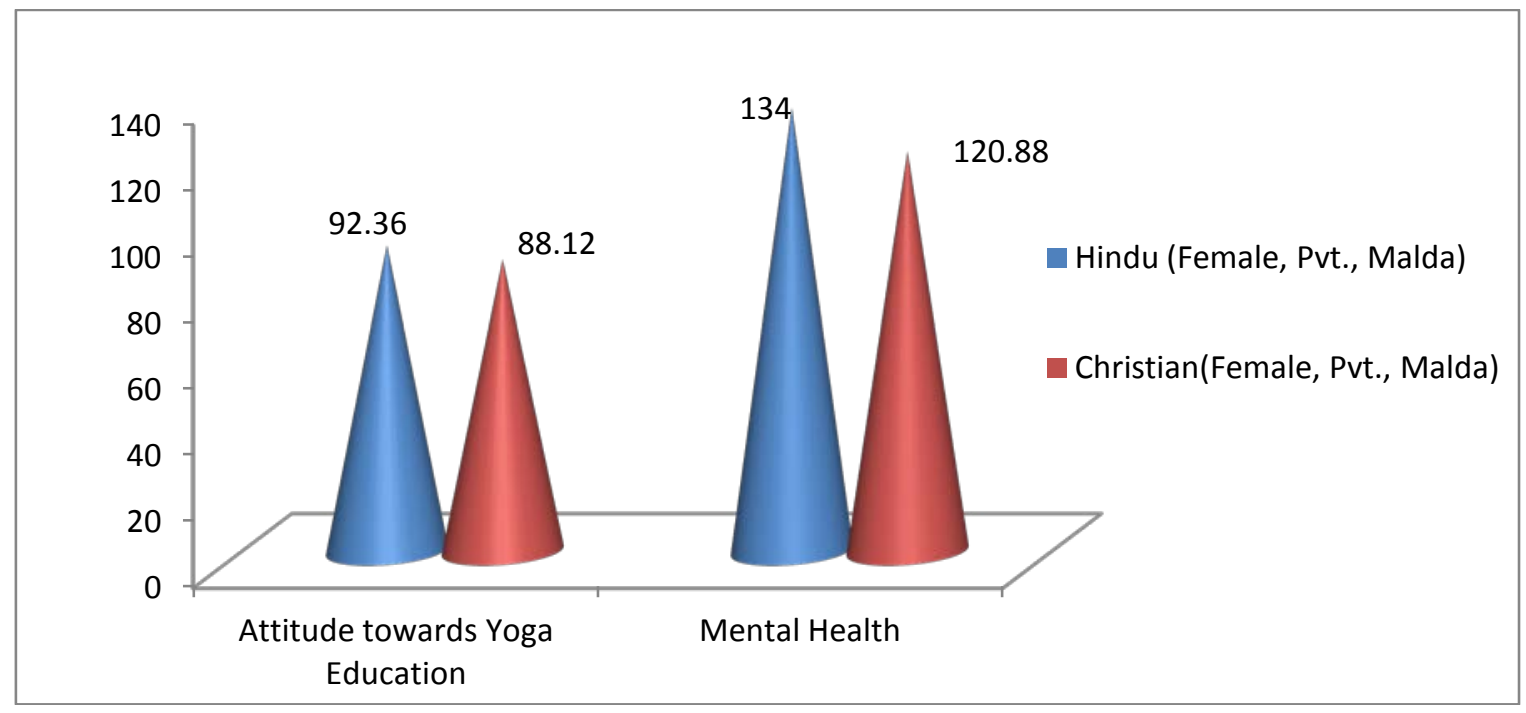

Fig. 2(iv): Difference in attitude between female, Hindu and Christian teachers in privately managed secondary schools in Malda district, W.B., India towards yoga education and their mental health.

The tables 1 (ii) and 1 (iv) above reveal that the Hindu teachers in privately managed schools show better attitude towards yoga education than their counterpart in government schools (Singh \& Dubey, 2015). However, the Christian teachers show slightly lower attitude here. Whereas the tables 1 (iii) and 1(iv) reveals that the female Hindu teachers in privately managed schools show better attitude towards yoga education than their male counterpart (Singh, 2017).

Table VI: The table below depicts the comparison in attitude between Hindu vs. Christian male teachers in government managed secondary schools in Murshidabad district, West Bengal, India, towards yoga education in secondary schools vis-à-vis their mental health:

\begin{tabular}{|c|c|c|c|c|c|c|c|c|c|}
\hline \multirow{2}{*}{$\begin{array}{c}\text { Comparison } \\
\text { Between } \\
\text { Groups } \\
\end{array}$} & \multirow{2}{*}{$\begin{array}{c}\text { Sample } \\
\text { No. }\end{array}$} & \multicolumn{6}{|c|}{ Attitude towards Yoga Education } & \multicolumn{2}{|c|}{ Mental Health } \\
\hline & & Mean & S. D. & Variance & Df & F-value & t-value & Score (Av.) & Type \\
\hline Hindu & 25 & 103.24 & 8.18 & 66.91 & \multirow{2}{*}{48} & \multirow{2}{*}{121.46} & \multirow{2}{*}{$11.02 *$} & 119.40 & Very Poor \\
\hline Christian & 25 & 83.48 & 3.66 & 13.40 & & & & 120.76 & Very Poor \\
\hline
\end{tabular}

From table it can be inferred that there is a significant difference in attitude towards yoga education at 0.01 level between male, Hindu (103.24 \pm 8.18) and Christian (83.48 \pm 3.66) teachers in government managed secondary schools in Murshidabad district. The teachers with better mental health
(Christian, 120.76) show lower attitude (83.48) towards yoga education than the teachers with lower mental health (Hindu, 119.40). This attitudinal difference is pictorially presented in fig. $2(\mathrm{v})$ below. 


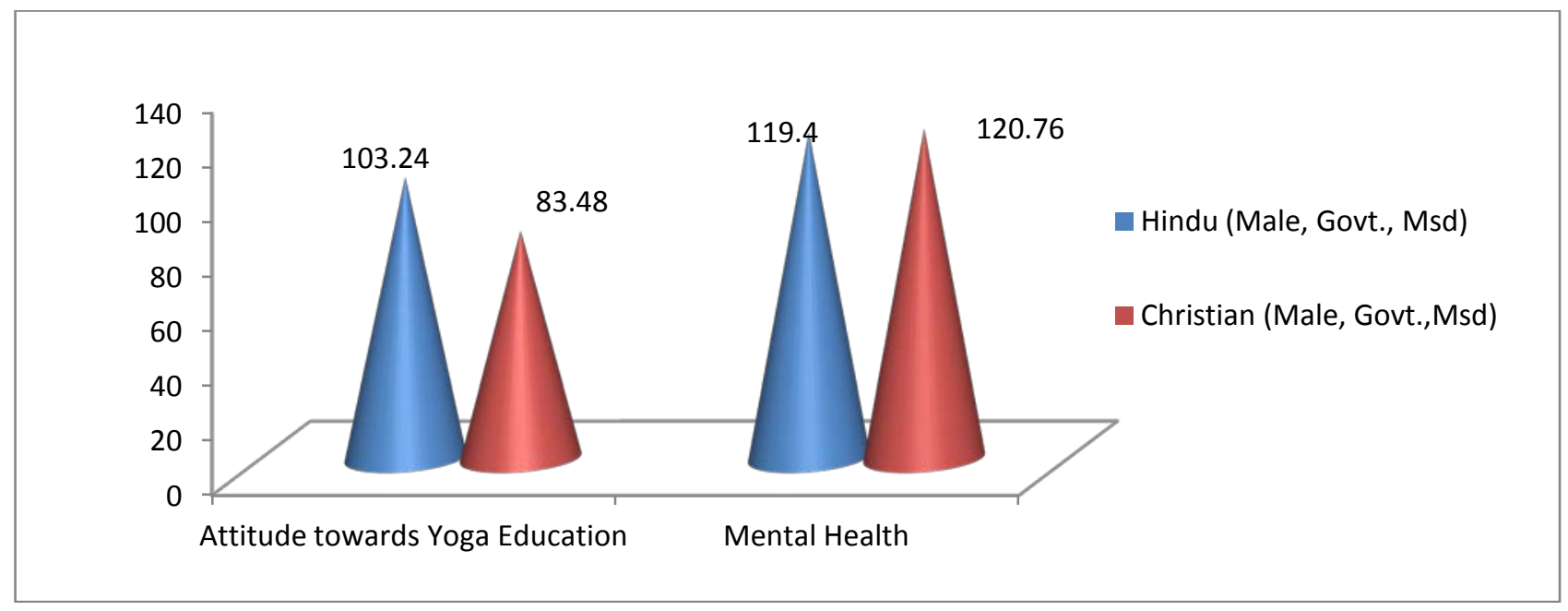

Fig. 2(v): Difference in attitude between male, Hindu and Christian teachers in govt. managed secondary schools in Murshidabad district, W.B., India, towards yoga education and their mental health.

Table VII: The table below depicts the comparison in attitude between Hindu vs. Christian female teachers in government managed secondary schools in Murshidabad district, West Bengal, India, towards yoga education in secondary schools vis-à-vis their mental health:

TABLE VII ATTITUDE BETWEEN HINDU VS. CHRISTIAN FEMALE TEACHERS IN GOVERNMENT MANAGED SECONDARY SCHOOLS

\begin{tabular}{|c|c|c|c|c|c|c|c|c|c|}
\hline \multirow{2}{*}{$\begin{array}{l}\text { Comparison } \\
\text { Between } \\
\text { Groups } \\
\end{array}$} & \multirow{2}{*}{$\begin{array}{c}\text { Sample } \\
\text { No. }\end{array}$} & \multicolumn{6}{|c|}{ Attitude towards Yoga Education } & \multicolumn{2}{|c|}{ Mental Health } \\
\hline & & Mean & S. D. & Variance & Df & F-value & t-value & Score (Av.) & Type \\
\hline Hindu & 25 & 91.16 & 8.01 & 64.16 & \multirow{2}{*}{48} & \multirow{2}{*}{3.05} & \multirow{2}{*}{$1.75 *$} & 117.28 & Very Poor \\
\hline Christian & 25 & 88.00 & 4.21 & 17.72 & & & & 120.00 & Very Poor \\
\hline
\end{tabular}

From table there is no significant difference in attitude towards yoga education at 0.05 level between the female, Hindu $(91.16 \pm 8.01)$ and Christian $(88 \pm 4.21)$ teachers in government managed secondary schools in Murshidabad district. The teachers with better mental health (Christian,
120.00) show lower attitude (88.00) towards yoga education than the teachers with lower mental health (Hindu, 117.28). This attitudinal difference is pictorially presented in fig.2 (vi) below:

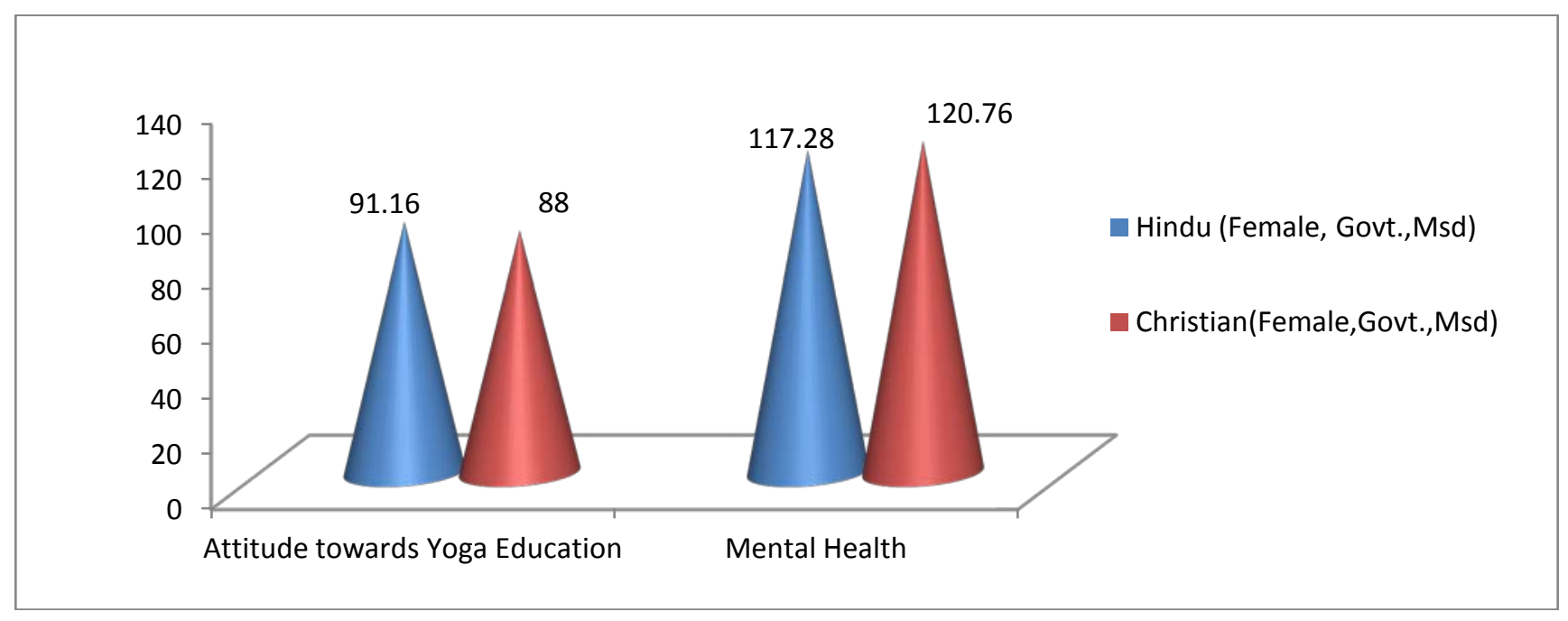

Fig. 2 (vi): Difference in attitude between female, Hindu and Christian teachers in govt. managed secondary schools in Murshidabad district, W.B., India, towards yoga education and their mental health 
Tables 1(v) and 1(vi) clearly shows that the female Christian teachers in govt. schools show better attitude towards yoga education than their male counterpart (Patel, 2017) in comparison to their Hindu colleague.
Table VIII: The table below depicts the comparison of attitude between Hindu vs. Christian, male teachers of the privately managed secondary schools in Murshidabad district, West Bengal, India, towards yoga education in secondary schools vis-à-vis their mental health:

TABLE VIII ATTITUDE BETWEEN HINDU VS. CHRISTIAN, MALE TEACHERS OF THE PRIVATELY MANAGED SECONDARY SCHOOLS

\begin{tabular}{|l|c|c|c|c|c|c|c|c|c|}
\hline $\begin{array}{c}\text { Comparison } \\
\text { Between } \\
\text { Groups }\end{array}$ & \multirow{2}{*}{$\begin{array}{c}\text { Sample } \\
\text { No. }\end{array}$} & \multicolumn{6}{|c|}{ Attitude towards Yoga Education } & \multicolumn{2}{|c|}{ Mental Health } \\
\cline { 3 - 11 }$y$ & Mean & S. D. & Variance & Df & F-value & t-value & Score (Av.) & Type \\
\hline Hindu & 25 & 89.12 & 7.12 & 50.69 & \multirow{2}{*}{48} & 6.24 & $2.50 *$ & 134.36 & Poor \\
\hline Christian & 25 & 85.04 & 4.01 & 16.08 & & & & 114.44 & Very Poor \\
\hline
\end{tabular}

The table depicts that there is a significant difference in attitude towards yoga education at 0.05 level between male, Hindu (89.12 \pm 7.12$)$ and Christian (85.04 \pm 4.01$)$ teachers in privately managed secondary schools in Murshidabad district. The better mental health type teachers (Hindu, 134.36) show better attitude (89.12) towards yoga education than the teachers with lower mental health (Christian, 114.44). This attitudinal difference is pictorially presented below in fig.2 (vii):

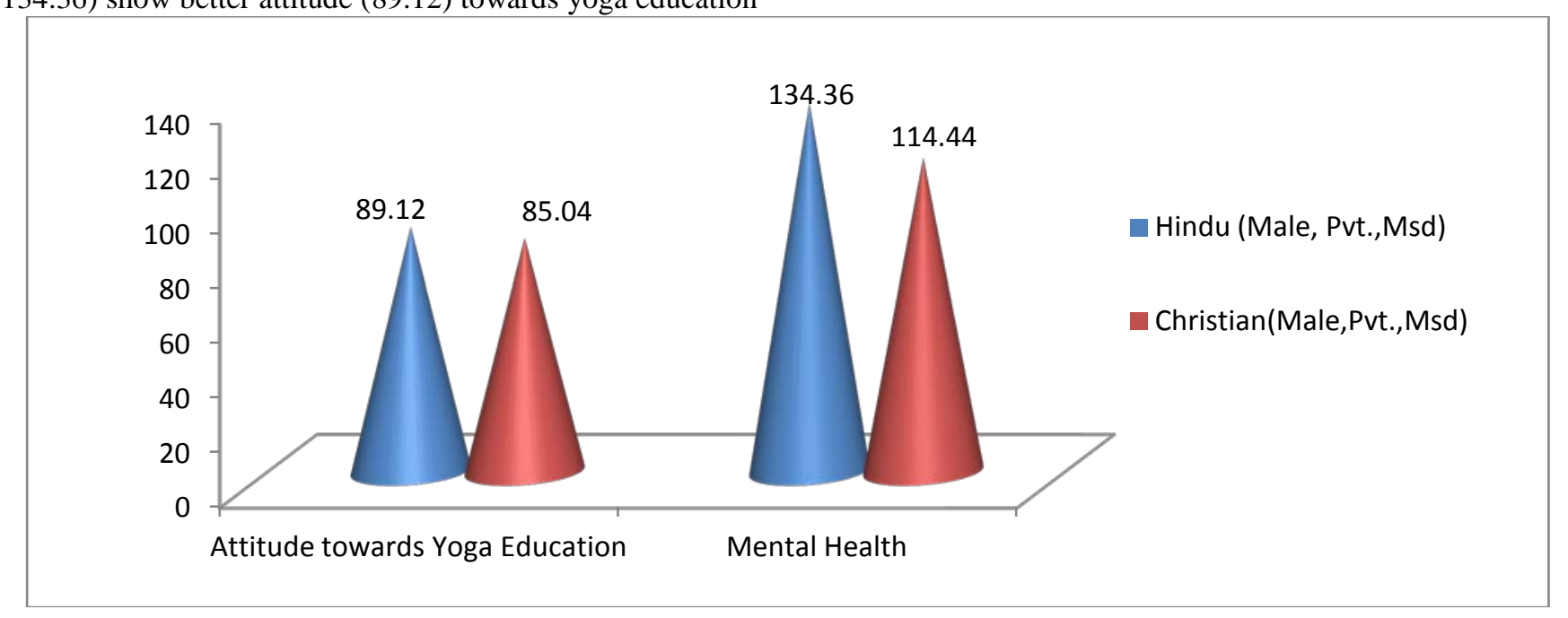

Fig. 2(vii): Difference in attitude between male, Hindu and Christian teachers in privately managed secondary schools in Murshidabad district, W.B., India, towards yoga education and their mental health

The tables $1(\mathrm{v})$ and 1 (vii) above reveal that the Christian teachers in privately managed schools show better attitude towards yoga education than their government counterpart (Singh \& Dubey, 2015). However, the attitude of the Hindu teachers shows a reverse trend.
Table IX: The table below depicts the comparison in attitude between Hindu vs. Christian female teachers in privately managed secondary schools in Murshidabad district, West Bengal, India, towards yoga education in secondary schools vis-à-vis their mental health:

TABLE IX ATTITUDE BETWEEN HINDU VS. CHRISTIAN FEMALE TEACHERS IN PRIVATELY MANAGED SECONDARY SCHOOLS

\begin{tabular}{|c|c|c|c|c|c|c|c|c|c|}
\hline \multirow{2}{*}{$\begin{array}{c}\text { Comparison } \\
\text { Between } \\
\text { Groups } \\
\end{array}$} & \multirow{2}{*}{$\begin{array}{c}\text { Sample } \\
\text { No. }\end{array}$} & \multicolumn{6}{|c|}{ Attitude towards Yoga Education } & \multicolumn{2}{|c|}{ Mental Health } \\
\hline & & Mean & S. D. & Variance & Df & F-value & t-value & Score (Av.) & Type \\
\hline Hindu & 25 & 99.92 & 11.47 & 131.56 & \multirow{2}{*}{48} & \multirow{2}{*}{19.45} & \multirow{2}{*}{$4.41^{*}$} & 118.72 & Very Poor \\
\hline Christian & 25 & 88.76 & 5.35 & 28.62 & & & & 113.08 & Very Poor \\
\hline
\end{tabular}

The table illustrates that there is a significant difference in attitude towards yoga education at 0.01 level between the female, Hindu (99.92 \pm 11.47) and Christian (88.76 \pm 5.35) teachers in privately managed secondary schools in Murshidabad district. The teachers with better mental health
(Hindu, 118.72) show better attitude (99.92 \pm 11.47) towards yoga education than the teachers with lower mental health (Christian, 113.08). This attitudinal difference is pictorially presented in fig.2 (viii) below: 


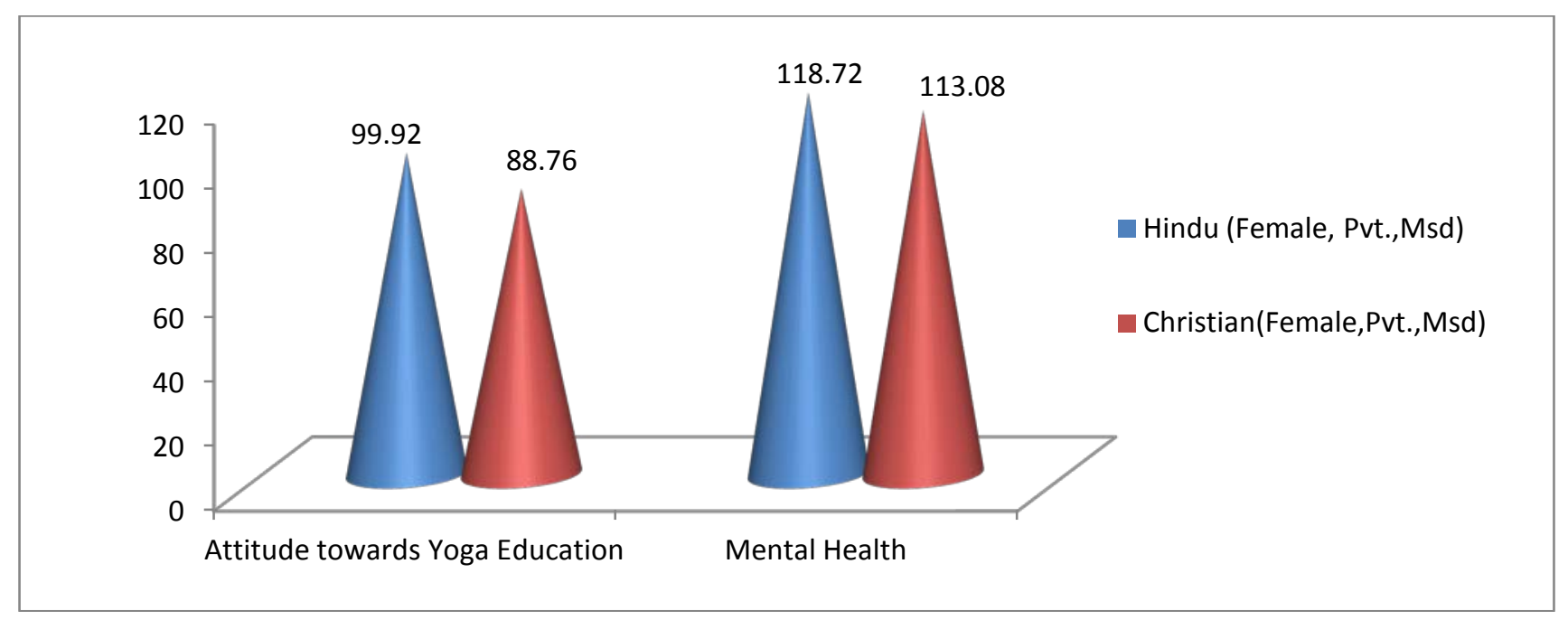

Fig. 2(viii): Difference in attitude between female, Hindu and Christian teachers in privately managed secondary schools in Murshidabad district, W.B., India, towards yoga education and their mental health

The tables 1(vi) and 1(viii) above reveal that both the Hindu and Christian teachers in privately managed schools show better attitude towards yoga education than their counterparts in government schools (Singh \& Dubey, 2015). Similarly, tables 1(vii) and 1(viii) further show that the female teachers in private schools, belonging to both the religious identifications (Hindu and Christian) possess better attitude towards yoga education than their male counterpart (Singh, 2017).

\section{CONCLUSION}

There is a significant difference in attitude towards yoga education at 0.01 levels between Hindu and Christian teachers in secondary schools in Malda and Murshidabad districts, West Bengal, India. The better mental health possessing Hindu teachers show better attitude towards yoga education than their Christian counterpart. The male teachers in government schools in Malda and Murshidabad districts show significant difference in attitude towards yoga education in schools than their female counterpart. However, there is no significant difference in attitude towards yoga education in schools between the male and female teachers (Hindu vs. Christian) in private schools (Gray, 2013, Gandge \& Parihar, 2016, Kerketta, et al., 2016) in Malda district. On the other hand, a significant difference was observed in attitude towards yoga education between Hindu and Christian teachers of both sexes in privately managed schools in Murshidabad district.

\section{ACKNOWLEDGEMENT}

The financial assistance from the Indian Council of Social Science Research (ICSSR), MHRD, and New Delhi to carry out a major research project on teachers' attitude towards yoga education in secondary schools in Malda and Murshidabad districts, W.B., India under the directorship of this author is duly acknowledged here. Without this financial assistance it was not possible to complete this paper.

\section{REFERENCES}

[1] Gandge, K.N., \& Parihar, V.R. (2016). The Attitude of College Sports Participated Students Towards Yoga: A Study. International Referred Online Research Journals. http://onlineresearchjournalsssm.in/?p=6608

[2] Gray, A. (2013). Undergraduate Psychology Students' Attitudes toward Yoga in the Classroom. Middle Tennessee State University: Ph.D. Thesis. http://gradworks.umi.com/15/38/1538323.html

[3] Kerketta, M., Yadav, I., \& Yadav, S.K.S. (2016). Attitude of male and female students of Guru Ghasidas Vishwavidyalaya towards Yoga. International Journal of Physical Education and Sports, $1(1), 14-17$.

[4] Khatun, A. (2016). A study on the attitude of teacher-students towards yoga education. International Journal of Yoga, Physiotherapy and Physical Education, 1(1), 38-39.

[5] Patel, M.K.M. (2017). Attitude towards Yoga among Primary teachers with regards to Gender, Area of Residence and Age. Journal of Information, Knowledge and Research in Humanities and Social, 4(2), 273-276.

[6] Singh, M.K. and Dubey, S. (2016). Analytic Study of Attitude towards Yoga between the Male Students of Selected Government and Private Schools of Bilaspur. International Journal of Physical Education, Sports and Health, 3(1), 250-251.

[7] Singh, Y.C. (2017). A Study of Yoga Attitude of Secondary School Students in South Tripura District. International Journal of Research in Social Sciences, 7(9), 233-239. 